\title{
The selective advantage of body-part terms
}

\author{
Mark Dingemanse \\ Max Planck Institute for Psycholinguistics, Nijmegen, The Netherlands
}

Received 24 April 2008; received in revised form 4 November 2008; accepted 25 November 2008

\begin{abstract}
This paper addresses the question why body-part terms are so often used to talk about other things than body parts. It is argued that the strategy of falling back on stable common ground to maximize the chances of successful communication is the driving force behind the selective advantage of body-part terms. The many different ways in which languages may implement this universal strategy suggest that, in order to properly understand the privileged role of the body in the evolution of linguistic signs, we have to look beyond the body to language in its socio-cultural context. A theory which acknowledges the interacting influences of stable common ground and diversified cultural practices on the evolution of linguistic signs will offer the most explanatory power for both universal patterns and language-specific variation.
\end{abstract}

(C) 2008 Elsevier B.V. All rights reserved.

Keywords: Language change; Language evolution; Body-part terms; Body; Culture; Cognition

\section{Introduction}

Body-part terms are often used to talk about other things than body parts. Examples of this can be readily found in such everyday English expressions as 'the foot of the hill' and 'the head of the organisation' and in fact, it has been long recognized that the tendency is universal (de Witte, 1948). Consider the following examples ${ }^{1}$ from Yoruba, a Niger-Congo language spoken in Nigeria (Dingemanse, 2006):

$1 \quad$ e yà sí apá òtún <apá 'arm' $2 \mathrm{sg}$ turn to side left

'turn to the left'

$$
\begin{aligned}
& \text { ojú omi ni mo wà <ojú 'face' } \\
& \text { surface water be 1sg be.located } \\
& \text { 'I was on the high seas' }
\end{aligned}
$$

\footnotetext{
A first version of this paper was circulated in June 2006.

E-mail address: mark.dingemanse@mpi.nl.

${ }^{1}$ The following abbreviations are used in glosses: 1, 2, 3 1st, 2nd, 3rd person; Do direct object; IDPH ideophone; pl plural; POss possessive pronoun; sg singular.

Yoruba examples accord with Yoruba orthography. Thus, a dot under certain characters is used as a diacritic in representing the close vowels [ $\varepsilon$ ] and [ 0 ] (e and $\rho$ ) and the postalveoloar fricative [ $\left.\int\right]$ (s). Nasal vowels are represented by their oral counterparts followed by $n$, e.g. in, on except when the nasal vowel is preceded by the allophone [n] of /1/ so that [inú] 'belly' is written inú. Most other orthographic symbols have their IPA value, except for the following: $\mathrm{p}=[\mathrm{kp}], \mathrm{j}=[\mathrm{\jmath}], \mathrm{y}=[\mathrm{j}]$. High tone is marked by an acute accent [']), low tone by the grave accent ['], and mid is unmarked.
} 
The explanation usually advanced for this phenomenon is as commonplace as intuitive: it has to do with the primacy of bodily experience. Instances of essentially this same explanation can be found in widely divergent approaches to language and human cognition; for now, three examples will suffice. The German philosopher Ernst Cassirer wrote in his Philophie der symbolische Formen '[d]as Innen und Aussen, das Vorn und Hinten, das Oben und Unten erhält seine Bezeichnung dadurch, dass sie je an ein bestimmtes sinnliches Substrat im Ganzen des menschlichen Leibes angeknüpft werden'² (Cassirer, 1923:156). Similarly, the phenomenologist philosopher Merleau-Ponty attributed the importance of the body in language to the centrality of the body in both experience and expression—for it is only through the body that our inner life can manifest itself outwards (Merleau-Ponty, 1945:226). And lastly, the cognitive linguistic tenet that 'our conceptualization of entities in more abstract domains is based on concrete concepts which are more clearly delineated in our experience' (Lakoff and Johnson, 1980:112) is basically the same statement. However, what does it really mean to resort to this 'primacy of bodily experience'? While the preponderance of body-part terms and their derivates in language has been widely recognized, the processes responsible for it have not received nearly as much attention. The present paper is intended as a contribution towards spelling out these processes; it considers body-part terms in the light of more general accounts of semiotics (Keller, 1994, 1998), language change (Croft, 2000), and human cognition (Tomasello, 1999, 2008).

The rest of the paper is laid out as follows: section 2 starts with a brief overview of some basic theoretical prerequisites and goes on to consider the role of the body in the evolution of linguistic signs. Section 3 fleshes out a special aspect of certain body-part terms that further contributes to their 'fitness'. The fourth and last section takes a broader view and examines the factors responsible for variation in secondary uses of body-part terms across languages, concluding that, in order to properly understand the privileged role of the body in language, one needs to look beyond the body to language in its social context.

\section{The role of the body in the evolution of linguistic signs}

To set the stage for the rest of the paper, I will first clarify some basic terms. Linguistic signs, in the perspective taken here, are 'the unintended results of a large number of intentional communicative acts' (Keller, 1998:88). ${ }^{3}$ To put it differently, we do not usually create words to communicate; rather, they arise in communication because they happen to serve our communicative goals. Communication, briefly defined, is the joint act of solving a coordination problem (Clark, 1996). The coordination problem here lies in the fact that speaker and hearer cannot read each other's mind, and that in speaking and understanding, they are trying to coordinate on the same meaning. Because communication is a joint act, the linguistic signs which arise from it are intersubjective and socially constituted (Tomasello, 1999:125). To say that linguistic signs are socially constituted means that convention (from the perspective of the individual definable as conformity to a community behaviour) is one of the central coordination solving devices of communication. As Croft puts it, '[c]onvention-whether conforming to it, violating it, or establishing it—plays a key role in language use and in language change' (Croft, 2000:7).

Convention, however, does not come into existence spontaneously; it needs to be established. The first use of a word or phrase with a particular meaning is not a conventional use by definition, as it does not involve conforming to an existing community behaviour. In such cases, communication can only succeed by means of non-conventional coordination solving devices. The most important of such devices available to humans is joint salience. That is, the ideal solution to the coordination problem of communication is the one "that is most salient with respect to the participants' current common ground" (Clark, 1996:66). Joint salience is different from salience simpliciter in that it is dependent on the common ground of participants, which in turn depends on shared experiences and knowledge. Common ground thus can differ from situation to situation. There are however some pieces of common ground that are relatively stable; and these can be recruited by participants in a coordination problem to fall back upon in the absence of convention.

This is where the body comes into the picture; for the body, of course, is a provider of solidly dependable common ground. As a physical universal of great cognitive and cultural salience (de Witte, 1948; Enfield et al., 2006;

\footnotetext{
2 'Inside and outside, front and back, top and bottom acquire their meaning from the fact that each of them is tied to a specific sensual substrate in the human body.' See also Senft (1997:4), who notes that much earlier, Immanuel Kant similarly linked spatial perception and cognition to the body in a pamphlet against Leibniz titled Von dem ersten Grunde des Unterschiedes der Gegenden im Raume [On the foundation of the discerning of objects in space].

${ }^{3}$ Compare Merleau-Ponty's statement that 'langages (...) sont le dépôt et la sédimentations des actes de parole' [languages ... are the deposit and the sediments of acts of parole] (1945:229, emphasis in original).
} 
Wierzbicka, 2007), the body is a very suitable source domain for expressing a variety of things. It jumps out at us, so to speak, as the ultimate common ground to resort to in solving our communicative coordination problems. This is what provides body-part terms with a selective advantage above certain other words in the evolution of linguistic signs.

Let me illustrate the logic of the pragmatic process at this point with an imaginary example from Yoruba. Imagine that at one point in time, a Yoruba speaker found herself wanting to say something about the front of her house (ilé). At a loss for words, she put together a novel phrase using some jointly salient entity as a metaphor for what she wanted to get at. She chose iwájú ilé, 'forehead of the house'. Her interlocutor, recognizing that she fell back on a nonconventional coordination solving device, could construct the meaning 'front part of the house' on the basis of the regularity of the imagery she used. ${ }^{4}$ Conceivably, this metaphorical use of iwájú 'forehead' caught on and spread through the population, rendering the source word polysemous. ${ }^{5}$

Of course, this example oversimplifies things in a number of ways: for one, it idealizes the speaker-hearer scenario; also, precisely because of the selective advantage of body-part terms, we may expect this process to occur several times independently throughout the population; furthermore, people differ in their past experiences so that for one person the expression may be more conventionalized than for another; and lastly, this example focuses on one word whereas in fact it may well be that the relevant unit is a construction, or a 'pattern' in corpus linguistic terms (Hilpert, 2006). What the example makes clear, however, is how the strategy of falling back on stable common ground to maximize the chances of successful communication can be the driving force behind the selective advantage of body-part terms.

\section{The intertwining of two representational systems}

From a semiotic point of view, certain body-part terms are especially remarkable because they combine two representational systems at the disposal of humans. The first concerns a basic cognitive ability which humans share with many other species: the capacity to use information from the environment to preview candidate acts. ${ }^{6}$ This capacity is described by Tomasello as follows:

'The ability of organisms to operate not only with perceptions of the environment but also with sensory-motor representations of the environment - especially object categories and image schemas of dynamic events - is one of the most remarkable phenomena of the natural world. Most importantly, it gives organisms the ability to profit from personal experience via memory and categorization and so to be less dependent on Nature's ability to foresee the future via specific, and often inflexible, biological adaptations.' (Tomasello, 1999:125)

Both Tomasello and Keller (Keller, 1998:127-8) make a distinction between the capacity of sensory-motor representation on the one hand, and language (which Keller calls, after Bickerton, a secondary representation system) on the other hand. Of course, 'sensory-motor representation' is a term covering many different forms of representation $^{7}$ : Tomasello mentions object categories (many mammalian species form categories of perceptual and motor experiences, Tomasello, 1999:16-17) and image schemas; additionally, most of the types of body knowledge identified by psychologists fit in here. In this sense, the individual has internal sensory-motor representations of parts of the body; furthermore, it may be expected that these representations are especially salient for those body parts that are of high utility. The common feature of all of these representations is that they provide the individual with the ability to profit from personal experience in engaging with the world. Importantly, they are strictly private.

\footnotetext{
${ }^{4}$ Note that this common extension is found in English too: 'front' has its origin in Latin frons 'forehead' (Senft, 1997:19 and references cited therein). I will come back to universality and particularity in such semantic extensions in $\$ 4$ below.

${ }^{5}$ In Yoruba, spatial relations like this are usually expressed by means of a simple associative construction. In this construction, there are some syntactic differences between body-part terms on the one hand and their spatial relational derivates on the other hand (Dingemanse, 2006:30-32). This is one of the reasons to analyze these terms as polysemous (the alternative - ruled out, I think, by the Yoruba data - would be to consider this process an instance of online extension).

${ }^{6}$ This goes further than just acting in real-time on the basis of direct perceptions of the environment, as it involves an inner selective environment in which the organism can 'test-run' possible behaviours or actions, thus 'weeding out the truly stupid options before risking them in the harsh world' as Daniel Dennett (1995:375-7) puts it. Dennett calls organisms with this capability (including mammals, birds, reptiles and fish) Popperian creatures, citing Popper who wrote that this design enhancement "permits our hypotheses to die in our stead".

${ }^{7}$ A terminological quibble: to some, the term representation carries with it some flavour of 'intentionality' or 'aboutness'. When understood in this sense, it evokes the philosophical problem of intentionality: how, or in virtue of what, do mental entities or structures relate to the outside world? This problem is avoided by a purely functional conception of representation as resulting from a process of structural coupling trough a history of recurring interactions between organism and environment (Foley, 1997:9-11, citing Varela et al., 1991).
} 
Traditionally, sensory-motor representation has been the domain of neurophysiologists and psychologists, whereas the secondary representation system, language, has been the domain of linguists. Indeed, the distinction seems straightforward enough in most cases. However, the fact that the two levels can be distinguished does not mean that there is an unbridgeable gap between them. As a matter of fact, numerous recent studies show that certain body-part terms bridge this gap in interesting ways. Morrison and Tversky (2005) had participants carry out verification and similarity tasks based on different kinds of stimuli. When given a visual cue (e.g., a picture of a human arm or a picture of a human body with the arm highlighted), participants made their judgments mainly on the basis of visual distinctiveness (i.e., part distinctiveness). However, when cued verbally (by a body-part term), their judgements were based mainly on part significance and function. Morrison \& Tversky note that this indicates that naming evokes function more than visual presentation does-and function of course is intimately linked to the sensory-motor level of representation. Their conclusion may be tentatively linked to recent fMRI/ERP experiments carried out by Tim Rohrer. Rohrer's findings show that certain areas of the sensorimotor cortex that can be correlated to body parts show neural activity not only upon tactile stimulation of the body part in question (e.g., the hand), but also during processing of linguistic stimuli in which body part terms (or verbs related to them) figure. Moreover, this activity is not only triggered by literal use (e.g., "he handed me the hammer'), but also (though - not unimportant - to a lesser extent) by stimuli involving metaphorical use (e.g., 'the student grasped the problem'). ${ }^{8}$ Rohrer concludes that the semantic processing of body-part language seems to require the active participation of the sensorimotor cortices (Rohrer, 2001:5).

There is also linguistic evidence suggestive of the importance of function in the semantic content of body-part terms. For example, as Enfield notes, 'idiomatic references to body parts often pick out precisely these functional components of meaning' (Enfield, 2006:196n9). This can be illustrated with a few examples from Yoruba. Thus, in the proverb in (3), the 'for transport' sense of esè 'leg/foot' is picked out; likewise, owó in (4) highlights the 'for doing' sense of 'hand'.

$$
\text { eșè girììì ni ilé ànjộfé }
$$

legs/feet IDPH.go.fast be house abundance

'many hurry to the house where free food and drinks are available'

\section{ó ràn mi l'ówó}

3sg help 1sgDo in-hand

'she helped me' (lit. 'she helped me in hand')

Framing this in more evolutionary terms, we may hypothesize that this feature makes certain body-part terms especially fit for the purpose of serving as a structural template to understand and describe other objects. Thus, the reason expressions like this work so well is essentially the one outlined in $\$ 2$ above: the strong functional component of the meaning of certain body-part terms is part of the common ground that helps communication succeed. What is interesting about this specific case however is that something that is in essence private (namely, sensory-motor representation) can apparently be of joint salience to speaker and hearer. This really reveals the power of the secondary representation system, in that it affords its users the possibility to tap into the resources of personal experience. Body-part terms thus are a special kind of linguistic sign: they represent the intertwining of the private system of sensory-motor representation on the one hand, and the public, socially constituted system of human language on the other hand. ${ }^{9}$

\section{A universal strategy with language-specific patterns}

For reasons sketched in the previous sections, figurative uses of body-part terms are widely attested in the languages of the world. In fact, assuming that speakers all over the world have the same basic communicative needs, the fact that every one of them can depend on the body as a source of joint salience might lead us to anticipate the widespread occurrence of similar patterns of semantic extension of body-part terms. To a certain degree, this expectation is borne out. Wilkins (1996) for example maps several common tendencies of semantic shifts in body-part terms. Hilpert (2007), in a survey of chained metonymies involving body-part terms, finds the following three extensions to be

\footnotetext{
${ }^{8}$ It should be noted that, although Rohrer (2001:3n2) reports that stimuli sets were designed for hand, feet, and face terms, only the results of the hand terms have been published so far (in Rohrer, 2001; cf. Rohrer, 2005).

${ }^{9}$ Note that body-part terms may differ in the extent to which they have this quality. These differences probably relate to the differences in size of the 'footprints' (neural maps) of body parts on the sensory-motor cortices, as shown in the famous homunculus images in Penfield and Rasmussen (1950). Of course, the heightened nerve density of certain body-parts is tightly interwoven with their functional significance in our daily life.
} 
especially widespread globally: BACK $\rightarrow$ BACK PART (attested in 42 of 76 languages), EYE $\rightarrow$ VISION (39/76), and MOUTH $\rightarrow$ SPEECH (32/76). Likewise, Heine (1997) notes that semantic extension of body-part terms is universal and hence, that 'we may expect this to be reflected in all languages' (Heine, 1997:142).

At the same time however, there appears to be much room for language-specific variation. Consider first the contrast between Mixtec (Oto-Manguean; Mexico) and Yélî Dnye (a Papuan isolate; Rossel Island). In Mixtec, the semantic extension of body-part terms to spatial relations is highly regular and systematic (Langacker, 2002:143), whereas in Yélî Dnye, very few body-part terms have taken on spatial meanings, and only marginally so (Levinson, 2006a,b:233). An example of variation on another plane is provided by the Yoruba expression ojú abéré,, literally 'eye of the needle'. Contrary to what most speakers of English would expect, this term does not refer to the hole the thread is pulled through, but rather to the sharp point of the needle. ${ }^{10}$ Other instances of this same extension, which may be characterized as EYE $\rightarrow$ ACTION POINT, are provided by such terms as ojú òbe \{eye knife\} 'knife-edge', òbe olójú méji \{knife poss-eye two\} 'double-edged knife', and ojú àáké \{eye hatchet\} 'edge of a hatchet-blade'. It appears to be quite salient to Yoruba speakers, whereas it is not at all that intuitive to English speakers. On the other hand, I am not aware of any expressions in Yoruba making use of the EYE $\rightarrow$ SMALL HOLE metaphor that is so common in English and other SAE languages. ${ }^{11}$

It is clear that language-specific patterns like these cannot be accounted for in terms of the joint salience resulting from physiological similarities between speaker and hearer, for this would lead us to expect similarities only. The two examples point to two additional factors that are at play, both of which involve situating language more firmly in its broader social context. First, the difference between Mixtec and Yélî Dnye indicates that having a body does not make it imperative to talk about the domain of space in terms of it. Another common strategy, for example, is to use environmental landmarks as a source domain (Heine, 1997). Yoruba provides a case in point: even though a lot of its spatial relational terms are historically related to body-part terms, certain common spatial terms have been derived from environmental landmarks, including òkè ‘top' ( < 'mountain') and ilè ‘below, down' ( $<$ 'ground'). In other words, the body is not the only source of joint experiential salience. Sinha and Jensen de Lopez (2001), in their proposal to extend the embodiment hypothesis beyond the merely corporeal, make essentially the same point. Secondly, the 'eye of the needle' example shows that the possibility of variation lies not just in the different sources of joint experiential salience available. It would seem that the cultural conceptions of a speech community or a language area may also lead to certain paths of semantic extension becoming more likely than others. This calls for a refinement of Wilkins' (1996) important proposals on natural tendencies of semantic change. ${ }^{12}$ Clearly, it is not only natural tendencies, but also cultural tendencies that shape the paths of semantic change in linguistic systems. Culture is another important source of the joint salience at the disposal of speaker and hearer. And so, cultural practices that evolved in the interaction of people with their environment and with each other become part of what functions as the environment in the evolution of linguistic signs, shaping the fitness landscape and making room for variation (see Kirby et al., 2007).

The question of universals and variation is not a new one, of course. Dimmendaal, in a fascinating paper on the study of lexical-semantic fields, makes a comment that is worth quoting in full:

'Some might argue that universalists are interested in more widespread patterns, leaving "exceptions" to be further investigated, and possibly explained, by butterfly collectors. But the issue is not simply one of diverging

\footnotetext{
${ }^{10}$ The eye of the needle is called simply ihó abéré, 'hole (of) needle' in Yoruba. There is an interesting twist to this example. It turns out that the well-known Biblical saying that 'it is easier for a camel to go through the eye of a needle than for a rich man to enter the kingdom of God' (Luke 18:25) has been translated into Yoruba using ojú abéré, i.e., 'point of the needle'. One assistant with whom I discussed this during a field work session was rather surprised to learn that the English expression actually refers to the hole of the needle, for he had always been under the impression that the saying was something along the lines of 'it is easier for a camel to stand on the point of a needle (etc.)'. One has to admit that this is quite a difficult feat, too.

${ }^{11}$ A perhaps more common type of extension EYE $\rightarrow$ TIP is noted for Kilivila by Senft (1998:77). Fédry (1976) gives the extension MOUTH $\rightarrow$ ACTION POINT for the Chadian language Sàr (in fact, according to Abraham (1958) this extension is found in Yoruba too, cf. ẹnu ọbe \{mouth knife\} 'knife-edge'; I have not yet been able to determine the difference with the expression involving 'eye'). A 1995 posting on the Linguist List by Claude Boisson (vol. 6-158, 6 Feb 1995, Q1) identifies some 15 more languages in which this metaphor is attested; all in all, this seems to confirm the impression that its occurrence is somewhat limited.

${ }^{12}$ For Wilkins, these natural tendencies arise 'out of the universality of certain cognitive processes and/or out of universal traits to be found in the production and interpretation of fully contextualised natural discourse' (1996:226). Wilkins does note the possibility of 'culture-specific changes' (1996:272), but these do not play a role in his argumentation since the focus of his paper is on universal tendencies. I thank an anonymous reviewer for pointing out the affinity between the present paper and Wilkins' study. See also Evans (2003) for a more thoroughgoing approach to this issue.
} 
academic interests, it is of far more fundamental portée. The emphasis on common patterns has led to a negligence of the possible (cultural) significance of the differences.' (Dimmendaal, 1995:9) ${ }^{13}$

Wondering about the 'tremendous variation' found in languages all over the world, Dimmendaal hypothesizes that 'our cognitive system, as reflected in language, apparently leaves considerable space for local adaptation' (1995:22). The examples and processes reviewed in the present paper also suggest a greater role for culture than it is usually accorded. ${ }^{14}$

\section{Concluding remarks}

Starting from the simple observation that body-part terms are often recruited to talk about other things than the body, this paper has surveyed part of the 'fitness landscape' in the evolution of linguistic signs. The first part of the paper has argued that the fail-safe strategy of falling back on stable common ground to resolve communicative coordination problems is the main driving force behind the selective advantage of body-part terms. However, the many different ways in which languages may implement this universal strategy suggest that there is more at play.

The second part of the paper has argued that linguistic sign systems evolve not only against the stable background of joint experiential salience and human sociality (Enfield and Levinson, 2006); their evolution is just as well subject to the influence of culture. Linguistic signs thus take their shape and uses in the midst of the complex interplay of these two factors. ${ }^{15}$ This fits in well with twin-track theories of evolution (Cavalli-Sforza and Feldman, 1981; Durham, 1991, 1992), in which the evolutionary tracks of genes and cultural entities are seen to interact, with culture becoming part of the fitness landscape in which the replicators evolve. It also fits in with recent developments in computational models of language evolution. One recent model (Kirby, 2007) involves agents which are allowed choice over the semantics of expressions (rather than working with a predetermined set of meanings), allowing one to see how 'meanings as well as signals evolve culturally' (2007:265). This is an important advancement over previous idealised models which allowed for monolithic meaning spaces only.

Further development of such computational models of language change may benefit from careful descriptions of the different processes at play in the evolution of linguistic sign systems. This paper is intended as a humble contribution towards that goal. Conversely, linguistic theorizing about these processes will benefit from the insights offered by these models, for example the possibility to quantify the adaptive costs and benefits of certain communicative strategies. In the end, a theory that acknowledges the interacting influences of stable common ground as well as diversified cultural practices on the evolution of linguistic signs will probably offer the most explanatory power for both universal patterns and language-specific variation.

\section{Acknowledgements}

I am grateful to Arie Verhagen, Felix Ameka, Gunter Senft, Nick Enfield, and an anonymous reviewer for discussions and comments. The usual disclaimer applies.

\section{References}

Abraham, Roy C., 1958. Dictionary of Modern Yoruba. University of London Press, London. Cassirer, Ernst. 1923. Philosophie der symbolische Formen. Erster Teil: Die Sprache. Berlin.

Cavalli-Sforza, L.L., Feldman, M.W., 1981. Cultural Transmission and Evolution: A Quantitative Approach. Princeton University Press, Princeton. Clark, Herbert H., 1996. Using Language. Cambridge University Press, Cambridge.

Croft, William, 2000. Explaining Language Change: An Evolutionary Approach. Pearson Education Limited, Harlow.

Dennett, Daniel, 1995. Darwin's Dangerous Idea. Simon \& Schuster, New York.

\footnotetext{
${ }^{13}$ The context of this quotation consists of a critical review of universalist colour term research in the Berlin \& Kay framework; because Dimmendaal's comment has wider application, I have omitted part of the last sentence, which runs as follows '.. as manifested in the referential meaning of colours.'

${ }^{14}$ The influence of our cognitive constitution on language has long been recognized, to the point of some claiming that language is an "instinct", hard-wired into our brains. Only recently, the hypothesis that this influence is probably mutual has enjoyed renewed attention, for example in the work of John Lucy (1992a,b), cf. also such volumes as Gumperz and Levinson (1996), Pütz and Verspoor (2000) and Gentner and Goldin-Meadow (2003).

${ }^{15}$ See Enfield (2008) for an account that carefully teases apart various transmission biases at play in the structuration of sign systems.
} 
de Witte, Antonius J.J., 1948. De betekeniswereld van het lichaam: taalpsychologische, taalvergelijkende studie [The semantic realm of the body: a psycholinguistic and comparative linguistic study]. De Standaard/Het Spectrum, Antwerpen/Utrecht.

Dimmendaal, G.J., 1995. Studying lexical-semantic fields in languages: nature versus nurture, or where does culture come in these days. Frankfurter Afrikanistische Blätter 7, 1-28.

Dingemanse, Mark. 2006. The Body in Yoruba: a linguistic study. MA Thesis. Leiden University. Available at http://ideophone.org/dl?id=3.

Durham, William H., 1991. Coevolution: Genes, Culture, and Human Diversity. Stanford University Press, Stanford.

Durham, William H., 1992. Applications of evolutionary culture theory. Annual Review of Anthropology 21 (1), 331-353.

Enfield, Nick J., 2006. Lao body part terms. Language Sciences 28 (2-3), 181-200.

Enfield, Nick J., 2008. Transmission biases in linguistic epidemiology. Journal of Language Contact 2, 299-310.

Enfield, Nick J., Levinson, Stephen C., 2006. Roots of Human Sociality: Culture, Cognition, and Human Interaction. Berg, Oxford.

Enfield, Nick J., Majid, Asifa, van Staden, Miriam, 2006. Cross-linguistic categorisation of the body: introduction. Language Sciences 28 (2-3), 137-147.

Evans, Nicholas, 2003. Context, culture, and structuration in the languages of Australia. Annual Review of Anthropology 32, 13-40.

Fédry, Jacques, 1976. L'experience du corps comme structure du langage—essai sur la langue Sàr, Tchad. L'Homme 16 (1), $67-107$.

Foley, William A., 1997. Anthropological Linguistics: An Introduction. Blackwell, Malden.

Gentner, Dedre, Goldin-Meadow, Susan, 2003. Language in Mind: Advances in the Study of Language and Thought. MIT Press, Cambridge, MA.

Gumperz, John J., Levinson, Stephen C., 1996. Rethinking Linguistic Relativity. Cambridge University Press, Cambridge.

Heine, Bernd, 1997. Cognitive Foundations of Grammar. Oxford University Press, Oxford/New York.

Hilpert, Martin, 2006. Keeping an eye on the data: metonymies and their patterns. In: Stefanowitsch, Anatol, Gries, Stefan Th. (Eds.), Corpora in Cognitive Linguistics: Metaphor and Metonymy. Mouton de Gruyter, Berlin, pp. 120-146.

Hilpert, Martin, 2007. Chained metonymies in lexicon and grammar: a cross-linguistic perspective on body part terms. In: Radden, Günter (Ed.), Aspects of Meaning Construction. John Benjamins, Amsterdam, pp. 77-98.

Keller, Rudi., 1994. On Language Change: The Invisible Hand in Language. Routledge, London/New York.

Keller, Rudi, 1998. A Theory of Linguistic Signs. Oxford University Press, Oxford.

Kirby, Simon, 2007. The evolution of meaning-space structure through iterated learning. In: Lyon, Caroline, Nehaniv, Chrystopher L., Cangelosi, Angelo (Eds.), Emergence of Communication and Language. Springer, pp. 253-267.

Kirby, Simon, Dowman, Mike, Griffiths, Thomas L., 2007. Innateness and culture in the evolution of language. PNAS 104 (12), $5241-5245$.

Lakoff, George, Johnson, Mark, 1980. Metaphors We Live By. University of Chicago Press, Chicago.

Langacker, Ronald W., 2002. English and Mixtec locatives. In: Enfield, Nick J. (Ed.), Ethnosyntax. Oxford University Press, Oxford/New York, pp. 138-161.

Levinson, Stephen C., 2006a. Parts of the body in Yélî Dnye, the Papuan language of Rossel Island. Language Sciences 28 (2-3), 221-240.

Levinson, Stephen C., 2006b. The language of space in Yélî Dnye. In: Levinson, Stephen C., Wilkins, David (Eds.), Grammars of Space. Cambridge University Press, Cambridge, pp. 157-205.

Lucy, John A., 1992a. Grammatical Categories and Cognition: A Case Study of the Linguistic Relativity Hypothesis. Cambridge University Press, Cambridge.

Lucy, John A., 1992b. Language Diversity and Thought: A reformulation of the Linguistic Relativity Hypothesis. Cambridge University Press, Cambridge.

Merleau-Ponty, Maurice, 1945. Phénoménologie de la perception. Gallimard, Paris.

Morrison, Julie B., Tversky, Barbara, 2005. Bodies and their parts. Memory \& Cognition 33 (4), 696-709.

Penfield, Wilder G., Rasmussen, Theodore B., 1950. The Cerebral Cortex of Man: A Clinical Study of Localization of Function. MacMillan, New York.

Pütz, Martin, Verspoor, Marjolijn H. (Eds.), 2000. Explorations in Linguistic Relativity. John Benjamins, Amsterdam.

Rohrer, Tim, 2001. Understanding through the body: fMRI and ERP investigations into the neurophysiology of cognitive semantics. In: Paper Presented at the International Cognitive Linguistics Association, July. University of California, Santa Barbara.

Rohrer, Tim, 2005. Image schemata in the brain. In: Hampe, Beate, Grady, Joseph E. (Eds.), From Perception to Meaning: Image Schemas in Cognitive Linguistics 165-198.

Senft, Gunter, 1997. Introduction. In: Senft, Gunter (Ed.), Referring to Space: Studies in Austronesian and Papuan Languages. Clarendon Press, Oxford, pp. 1-38.

Senft, Gunter, 1998. Body and mind in the Trobriand Islands. Ethos 26 (1), $73-104$ (Language, Space, and Culture).

Sinha, Chris, Jensen de Lopez, Kristine, 2001. Language, culture, and the embodiment of spatial cognition. Cognitive Linguistics 11 (1-2), 17-41.

Tomasello, M., 1999. The Cultural Origins of Human Cognition. Harvard University Press, Cambridge, MA.

Tomasello, Michael, 2008. Origins of Human Communication. MIT Press.

Varela, Francisco J., Thompson, Evan, Rosch, Eleanor, 1991. The Embodied Mind: Cognitive Science and Human Experience. MIT Press, Cambridge, MA.

Wierzbicka, Anna, 2007. Bodies and their parts: An NSM approach to semantic typology. Language Sciences 29 (1), 14-65.

Wilkins, David P., 1996. Natural tendencies of semantic change and the search for cognates. In: Durie, Mark, Ross, Malcolm (Eds.), The Comparative Method Reviewed: Regularity and Irregularity in Language Change. Oxford University Press, Oxford, pp. $264-304$. 